\title{
Gastrointestinal Bacterial and Methanogenic Archaea Diversity Dynamics Associated with Condensed Tannin-Containing Pine Bark Diet in Goats Using 16S rDNA Amplicon Pyrosequencing
}

\author{
Byeng R. Min, ${ }^{1}$ Sandra Solaiman, ${ }^{1}$ Raymon Shange, ${ }^{1}$ and Jong-Su Eun ${ }^{2}$ \\ ${ }^{1}$ Department of Agricultural and Environmental Sciences, Tuskegee University, Tuskegee, AL, USA \\ ${ }^{2}$ Department of Animal, Dairy, and Veterinary Sciences, Utah State University, Logan, UT, USA
}

Correspondence should be addressed to Byeng R. Min; minb@mytu.tuskegee.edu

Received 16 July 2013; Revised 4 September 2013; Accepted 4 September 2013; Published 2 January 2014

Academic Editor: Isabel Sá-Correia

Copyright (C) 2014 Byeng R. Min et al. This is an open access article distributed under the Creative Commons Attribution License, which permits unrestricted use, distribution, and reproduction in any medium, provided the original work is properly cited.

\begin{abstract}
Eighteen Kiko-cross meat goats $(n=6)$ were used to collect gastrointestinal (GI) bacteria and methanogenic archaea for diversity measures when fed condensed tannin-containing pine bark (PB). Three dietary treatments were tested: control diet ( $0 \% \mathrm{~PB}$ and $30 \%$ wheat straw (WS); 0.17\% condensed tannins (CT) dry matter (DM)); 15\% PB and 15\% WS (1.6\% CT DM), and 30\% PB and $0 \%$ WS (3.2\% CT DM). A 16S rDNA bacterial tag-encoded FLX amplicon pyrosequencing technique was used to characterize and elucidate changes in GI bacteria and methanogenic archaea diversity among the diets. Proteobacteria was the most dominant phylum in goats with mean relative abundance values ranging from 39.7 (30\% PB) to 46.5\% (control) and 47.1\% (15\% PB). Other phyla individually accounted for fewer than $25 \%$ of the relative abundance observed. Predominant methanogens were Methanobrevibacter (75, 72, and $49 \%$ ), Methanosphaera (3.3, 2.3, and 3.4\%), and Methanobacteriaceae (1.2, 0.6 , and $0.7 \%$ ) population in control, 15 , and $30 \%$ $\mathrm{PB}$, respectively. Among methanogens, Methanobrevibacter was linearly decreased $(P=0.05)$ with increasing $\mathrm{PB}$ supplementation. These results indicate that feeding PB selectively altered bacteria and methanogenic archaeal populations in the GI tract of goats.
\end{abstract}

\section{Introduction}

Studies on gastrointestinal (GI) microorganisms have traditionally depended on the use of anaerobic cultivation techniques [1] which only can detect an estimated $11 \%$ of the total bacterial populations present in the rumen [2]. Molecular methodologies developed over the past decade now enable researchers to examine the diversity of the gut microflora independent of cultural methods. Bacterial diversities within the GI tract of humans $[3,4]$ and rumen of beef cattle $[5,6]$ have been investigated in recent years as a result of development of $16 \mathrm{~S}$ rDNA-based analysis, yet similar data on the microbiomes of bacteria and methanogenic archaea diversity in the lower GI tract of meat goats are limited. In addition, there is no clear information on the prevalence of methanogenic and microbial populations in the hindgut of animals other than human and swine.
Plant tannins (condensed (CT) and hydrolysable tannins) are polyphenolic compounds of relatively high molecular weight with the capacity to form complexes mainly with proteins due to the presence of a large number of phenolic hydroxyl groups [7]. They are ubiquitously spread in nutritionally important forage trees, shrubs, legumes, cereals, and tree barks. The effects of tannins on ruminant production have been extensively published in the past, and among them beneficial effects of tannins on animal production system have been much focused, with particular interest in their positive effects on protein metabolism, prevention of frothy bloat, and modification on rumen microbial population [7]. Microbial population changes in the gut when animals were fed CT-containing diets were reported using a $16 \mathrm{~S}$ PCR technique in sheep [8] and rat [9]. In addition, the use of rapid sequencing technologies combined with molecular methods is becoming a prevalent standard for evaluating 
TABLE 1: Chemical compositions of pine bark (PB), wheat straw (WS), bermudagrass hay (BGH), and experimental diets fed to Kiko crossbred male goat kids.

\begin{tabular}{|c|c|c|c|c|c|c|c|}
\hline \multirow{2}{*}{ Item } & \multicolumn{3}{|c|}{ Ingredient, \% } & \multicolumn{3}{|c|}{ Experimental diets $^{1}$} & \multirow{2}{*}{ SEM } \\
\hline & $\mathrm{PB}$ & WS & $\mathrm{BGH}$ & Control & $15 \% \mathrm{~PB}$ & $30 \% \mathrm{~PB}$ & \\
\hline \multicolumn{8}{|c|}{ Ingredient of the grain/PB mix, $\%$ as is } \\
\hline Ground PB & - & - & - & 0 & 15.0 & 30.0 & - \\
\hline Ground WS & - & - & - & 30.0 & 15.0 & 0 & - \\
\hline Corn & - & - & - & 20.0 & 20.0 & 20.0 & - \\
\hline Soybean meal & - & - & - & 18.5 & 20.0 & 21.0 & - \\
\hline Soy hulls & - & - & - & 4.5 & 5.0 & 4.0 & - \\
\hline Alfalfa meal & - & - & - & 5.0 & 3.0 & 3.0 & - \\
\hline Molasses & - & - & - & 6.0 & 6.0 & 6.0 & - \\
\hline Vitamin and mineral mix & - & - & - & 0.5 & 0.5 & 0.5 & - \\
\hline Salt & - & - & - & 0.5 & 0.5 & 0.5 & - \\
\hline $\mathrm{NH}_{4} \mathrm{Cl}$ & - & - & - & 0.5 & 0.5 & 0.5 & - \\
\hline $\mathrm{BGH}$ & - & - & - & 15.0 & 15.0 & 15.0 & - \\
\hline \multicolumn{8}{|c|}{ Chemical composition, \% DM $(n=3)$} \\
\hline Dry matter & 83.6 & 83.5 & 91.4 & 89.7 & 87.8 & 87.3 & 0.77 \\
\hline Crude protein & 1.2 & 4.1 & 7.3 & 15.7 & 16.8 & 16.1 & 0.41 \\
\hline Neutral detergent fiber & 78.6 & 79.0 & 69.2 & 35.0 & 31.8 & 27.5 & 1.77 \\
\hline Acid detergent fiber & 72.1 & 49.2 & 37.3 & 23.7 & 23.2 & 23.6 & 1.42 \\
\hline Ether extract & 1.65 & 0.42 & 1.51 & 2.3 & 2.6 & 2.5 & 0.25 \\
\hline Ash & 2.3 & 2.0 & 4.8 & 6.4 & 6.2 & 5.9 & 0.31 \\
\hline $\mathrm{NFC}^{2}$ & 17.1 & 16.7 & 19.1 & 42.1 & 42.5 & 47.1 & 1.91 \\
\hline Acid detergent lignin & 21.3 & 8.01 & 6.3 & 5.9 & 9.9 & 12.4 & 0.85 \\
\hline Condensed tannins ${ }^{3}$ & 10.3 & 0.03 & 0.04 & 0.19 & 1.63 & 3.20 & 0.19 \\
\hline
\end{tabular}

${ }^{1}$ Control $(0 \%$ PB), $15 \%$ PB, and 30\% PB on an as-fed basis. Except bermudagrass hay, all ingredients were incorporated in the grain mixes.

${ }^{2}$ Nonfiber carbohydrates $=100-\mathrm{CP}-\mathrm{NDF}-$ ether extract - ash.

${ }^{3}$ Condensed tannins (CT) are relative to a purified quebracho CT standard.

SEM: standard error of the mean.

the microbiome of animals [10]. However, there is still a lack of information on the microbial diversity in the gut of ruminants such as sheep and goats. To date, little research has been focused on changes in microbial population diversity, particularly methanogenic archaeal population, and no study has measured the fecal microbial population in response to feeding diets containing different dietary concentrations of CT-containing pine bark (PB). In our previous study, addition of $\mathrm{PB}$ in goat diets improved growth performance, reduced fecal egg counts, and favorably modified ruminal fermentation [11]. In the present study, therefore, we utilized a bacterial tag-encoded FLX-titanium amplicon pyrosequencing (bTEFAP) method that is able to perform diversity analyses of fecal microbial populations. We evaluated the fecal microbiomes from 18 Kiko-cross meat goats fed PB containing diets. Hence, our principal objective of this study was to measure the effects of CT-containing PB supplementation as a feed supplement on GI methanogenic archaea and bacterial diversity dynamics in meat goats.

\section{Materials and Methods}

Care and handling of all experimental animals were conducted under protocols approved by the Tuskegee University Institutional Animal Care and Use Committee.
2.1. Experimental Animals and Diets. Eighteen Kiko crossbred male goat kids (Capra hircus; initial body weight $(B W)=31.0 \pm 1.49 \mathrm{~kg}$ ) were stratified by BW and randomly assigned to one of 3 experimental treatment groups $(n=6)$. Goats were individually housed indoors in pens of approximately $1.2 \mathrm{~m}^{2}$ with elevated floors and were fed grain mixes with different amounts $(0,15$, and $30 \%$ dry matter (DM) PB) of $\mathrm{PB}$ and long bermudagrass hay (BGH; Cynodon dactylon) at $85: 15$ on an as-fed basis. An adjustment period of 4 weeks allowed goats to become acclimated to pen living and routine feeding and to allot time for proper diet adjustment prior to study initiation. In wk 1, all animals were fed a diet without PB (control diet). Starting on wk 2, in the adjustment period, experimental diets were gradually fed to animals in a stepwise increasing fashion, and at the end of wk 4 , all animals were fed whole, preassigned experimental diets (Table 1).

Experimental diets (Table 1) contained different amounts of the CT-containing ground $\mathrm{PB}$ replacing ground wheat straw (WS; Triticum aestivum). Experimental treatments included the control diet ( $0 \% \mathrm{~PB}), 15 \% \mathrm{~PB}$, and $30 \% \mathrm{~PB}$ on an as-fed basis. The WS contained negligible CT (0.03\%), but concentrations of neutral detergent fiber (NDF) and nonfiber carbohydrates were similar between PB and WS [11]. The fresh $\mathrm{PB}$ was donated by a wood-processing company (West Fraser Timber Co. Ltd., Opelika, AL) and air-dried under 
the shed before processing. Freshly dried PB (10.3\% CT) was ground (Hammer Mill Model 1250; Lorenz MFG Co., Benson, MN) to approximately $3 \mathrm{~mm}$ particle. The WS $(0.03 \%$ $\mathrm{CT})$ was also ground $(3 \mathrm{~mm})$ and incorporated in the grain mix portion of the diets. Concentration of CT in 15\% PB and $30 \%$ PB diets was $1.63 \%$ and $3.20 \%$ DM, respectively (Table 1). The inclusion rate of $\mathrm{PB}$ was chosen, as we previously reported that beneficial effects of CT in the diet on sheep performance may occur in the range of 2 to $4 \%$ CT of diet $\mathrm{DM}[7,11]$. Mixtures containing ground PB and WS were commercially prepared at the local feed mill (Eclectic Feed Mill, Eclectic, AL). Experimental diets met requirements of experimental animals for growth and $\mathrm{BW}$ gain according to the NRC [12]. Diets were isonitrogenous and isocaloric but differed in NDF, lignin, and CT concentrations; lignin and CT concentrations were greater in $15 \%$ and $30 \% \mathrm{~PB}$ rations, whereas NDF concentration was decreased compared with control diet.

2.2. Sample Collection and Laboratory Analysis. After completion of adaptation period for $4 \mathrm{wk}$, total fecal collection was performed for $7 \mathrm{~d}$ to all goats. Animals were fed once a day at 8:00 h and had free access to water and a trace mineral salt block. Grain mixes and hay were offered separately, and refusals were recorded daily. Amounts of feed offered were adjusted every day to maintain the preferred daily refusal rate of 5 to $10 \%$.

During the collection periods, total individual fecal sample from the metabolism crate was collected at 9:00 am $(24 \mathrm{~h}$ overnight collection) during $7 \mathrm{~d}$ with two different experimental periods. Feed and orts samples for individual animals were collected daily during the collection period, dried at $60^{\circ} \mathrm{C}$ for $48 \mathrm{~h}$, ground to pass a $1 \mathrm{~mm}$ screen (standard model 4; Arthur H. Thomas Co., Swedesboro, NJ), and stored for subsequent analyses. Daily portions of ground samples were composited for each animal and analyzed for DM, crude protein (CP), acid detergent lignin, ether extract, and ash according to the methods described by AOAC [13]. Nitrogen for diet sample was determined using a Kjeldahl $\mathrm{N}$, and $\mathrm{CP}$ was calculated by multiplying $\mathrm{N}$ by 6.25 . The NDF and $\mathrm{ADF}$ concentrations were sequentially determined using an ANKOM $^{200 / 220}$ Fiber Analyzer (ANKOM Technology, Macedon, NY). Sodium sulfate heat stable amylases (Sigma Aldrich Co., St. Louis, Mo) were used in the procedure for NDF determination and pretreatment with heat stable amylase (Type XI-A from Bacillus subtilis; Sigma-Aldrich Corporation, St. Louis, MO). Acetone (70\%) extractable CT in grain mixes were determined using a butanol-HCL colorimetric procedure $[7,11]$.

2.3. DNA Extraction. Genomic bacterial DNA was isolated from $0.3 \mathrm{~g}$ of fecal samples according to the method described in the Power soil DNA mini Kit (Power Soil, West Carlsbad, CA). Extracted DNA $(2 \mu \mathrm{L})$ was quantified using a Nanodrop ND-1000 spectrophotometer (Nyxor Biotech, Paris, France) and run on $0.8 \%$ agarose gel with $0.5 \mathrm{M}$ tris-borate-EDTA (TBE) buffer. The samples were then transported to the Research and Testing Laboratory (Lubbock, TX) for PCR optimization and pyrosequencing analysis. Bacterial tagencoded FLX amplicon pyrosequencing PCR was carried out according to procedure described previously $[10,14]$.

2.4. bTEFAP Sequencing PCR. The bTEFAP and data processing were performed as described previously [10]. All DNA samples were adjusted to $100 \mathrm{ng} / \mu \mathrm{L}$. A $100 \mathrm{ng}(1 \mu \mathrm{L})$ aliquot of each sample's DNA was used for a $50 \mu \mathrm{L}$ PCR reaction. The 16S universal eubacterial primers 530F ( $5^{\prime}$-GTG CCA GCM GCN GCG G) and 1100R ( $5^{\prime}$-GGG TTN CGN TCG TTG) were used for amplifying the $600 \mathrm{bp}$ region of $16 \mathrm{~S}$ rRNA genes. HotStar Taq Plus Master Mix Kit (Qiagen, Valencia, CA) was used for PCR under the following conditions: $94^{\circ} \mathrm{C}$ for $3 \mathrm{~min}$ followed by 32 cycles of $94^{\circ} \mathrm{C}$ for $30 \mathrm{sec} ; 60^{\circ} \mathrm{C}$ for $40 \mathrm{sec}$ and $72^{\circ} \mathrm{C}$ for $1 \mathrm{~min}$; and a final elongation step at $72^{\circ} \mathrm{C}$ for $5 \mathrm{~min}$. A secondary PCR was performed for FLX (Roche, Nutley, NJ) amplicon sequencing under the same condition by using designed special fusion primers with different tag sequences as: LinkerA-Tags-530F and LinkerB-1100R [10]. The use of a secondary PCR prevents amplification of any potential bias that might be caused by inclusion of tag and linkers during initial template amplification reactions. After secondary PCR, all amplicon products from different samples were mixed in equal volumes and purified using Agencourt Ampure beads (Agencourt Bioscience Corporation, MA).

2.5. bTEFAP FLX Massively Parallel Pyrosequencing. In preparation for FLX sequencing, the DNA fragments size and concentration were accurately measured by using DNA chips under a Bio-Rad Experion Automated Electrophoresis Station (Bio-Rad Laboratories, CA) and a TBS-380 Fluorometer (Turner Biosystems, CA). A sample of double-stranded DNA containing $9.6 \times 106$ molecules/ $\mu \mathrm{L}$ of average size $625 \mathrm{bp}$ was combined with 9.6 million DNA capture beads and then amplified by emulsion PCR. After bead recovery and bead enrichment, the bead-attached DNA was denatured with $\mathrm{NaOH}$, and sequencing primers were annealed. A two-region 454 sequencing run was performed on a $70 \times$ 75 GS PicoTiterPlate (PTP) by using a Genome Sequencer FLX System (Roche, Nutley, NJ). It should be noted that 100 total samples were run within this same FLX 2-region sequencing reaction. The additional 79 tagged samples were associated with unrelated studies. All FLX related procedures were performed according to manufacturer's instructions (Genome Sequencer FLX System). A custom script written in manufacture's instruction was utilized to generate all possible combinations of 10-mer oligonucleotide tags with GC \% between 40 and $60 \%$. From this pool 20 individual tags were chosen (Table 2).

The resultant individual sample after parsing the tags into individual FASTA files was assembled using CAP3. The ace files generated by CAP3 were then processed to generate a secondary FASTA file containing the tentative consensus (TC) sequences of the assembly along with the number of reads integrated into each consensus. The TC was required to have at least 3-fold coverage. The resulting TC FASTA for each sample was then evaluated using BLASTn [15] against a custom database derived from the RDP-II database [16] 
TABLE 2: Primer sequences utilized for goats samples during bTEFAP.

\begin{tabular}{|c|c|}
\hline Name & Primer sequence $\left(5^{\prime}-3^{\prime}\right)$ \\
\hline $454-\mathrm{F} 30$ & GCCTCCCTCGCGCCATCAGCGCACTACGTGTGCCAGCMGCNGCGG \\
\hline $454-\mathrm{F} 31$ & GCCTCCCTCGCGCCATCAGCGCAGCTGTTGTGCCAGCMGCNGCGG \\
\hline $454-\mathrm{F} 32$ & GCCTCCCTCGCGCCATCAGCGCATACAGTGTGCCAGCMGCNGCGG \\
\hline $454-\mathrm{F} 33$ & GCCTCCCTCGCGCCATCAGCGCATCTATAGTGCCAGCMGCNGCGG \\
\hline $454-\mathrm{F} 34$ & GCCTCCCTCGCGCCATCAGCGCATTGGTGGTGCCAGCMGCNGCGG \\
\hline 454-F35 & GCCTCCCTCGCGCCATCAGCGCCAGAAAAGTGCCAGCMGCNGCGG \\
\hline $454-\mathrm{F} 36$ & GCCTCCCTCGCGCCATCAGTGTGACGTACGTGCCAGCMGCNGCGG \\
\hline $454-\mathrm{F} 37$ & GCCTCCCTCGCGCCATCAGTGTGTGCATAGTGCCAGCMGCNGCGG \\
\hline 454-F38 & GCCTCCCTCGCGCCATCAGTGTGTCCTCAGTGCCAGCMGCNGCGG \\
\hline $454-\mathrm{F} 39$ & GCCTCCCTCGCGCCATCAGTGTGCATCACGTGCCAGCMGCNGCGG \\
\hline $454-\mathrm{F} 40$ & GCCTCCCTCGCGCCATCAGTGTGCCTAGAGTGCCAGCMGCNGCGG \\
\hline $454-\mathrm{F} 41$ & GCCTCCCTCGCGCCATCAGTGTACATAGTGTGCCAGCMGCNGCGG \\
\hline 454-F42 & GCCTCCCTCGCGCCATCAGTGTACATTGAGTGCCAGCMGCNGCGG \\
\hline $454-\mathrm{F} 43$ & GCCTCCCTCGCGCCATCAGTGTACATTGTGTGCCAGCMGCNGCGG \\
\hline $454-\mathrm{F} 44$ & GCCTCCCTCGCGCCATCAGTGTACCAACAGTGCCAGCMGCNGCGG \\
\hline 454-F45 & GCCTCCCTCGCGCCATCAGTGTACCAACTGTGCCAGCMGCNGCGG \\
\hline $454-\mathrm{F} 46$ & GCCTCCCTCGCGCCATCAGTGTACCAATCGTGCCAGCMGCNGCGG \\
\hline 454-F47 & GCCTCCCTCGCGCCATCAGTGTACCAGATGTGCCAGCMGCNGCGG \\
\hline $454-\mathrm{F} 48$ & GCCTCCCTCGCGCCATCAGTGTACCCATAGTGCCAGCMGCNGCGG \\
\hline 454-F49 & GCCTCCCTCGCGCCATCAGTGTACAGGGTGTGCCAGCMGCNGCGG \\
\hline $454-\mathrm{F} 50$ & GCCTCCCTCGCGCCATCAGTGTACCTATCGTGCCAGCMGCNGCGG \\
\hline linkerB-1100R & GCCTTGCCAGCCCGCTCAGGGGTTNCGNTCGTTG \\
\hline
\end{tabular}

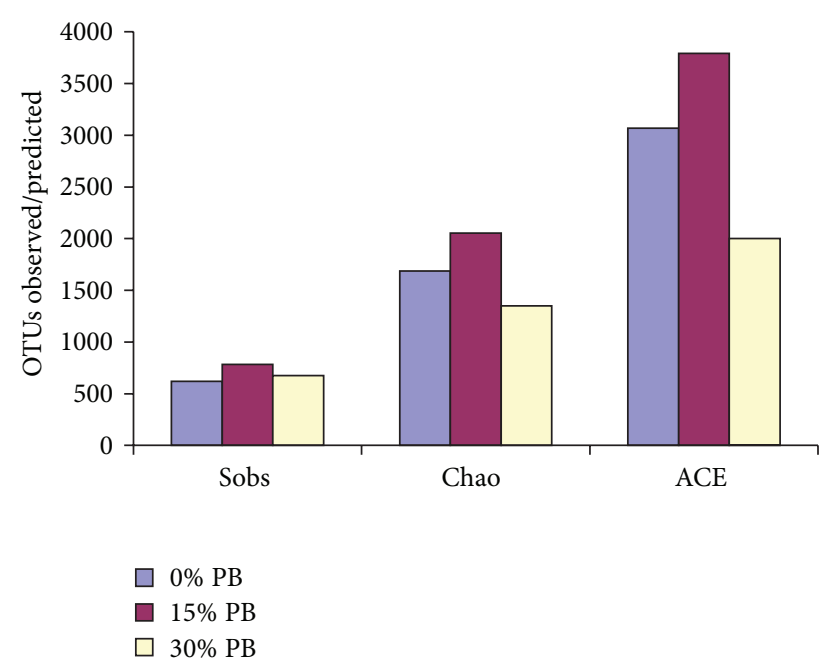

(a)

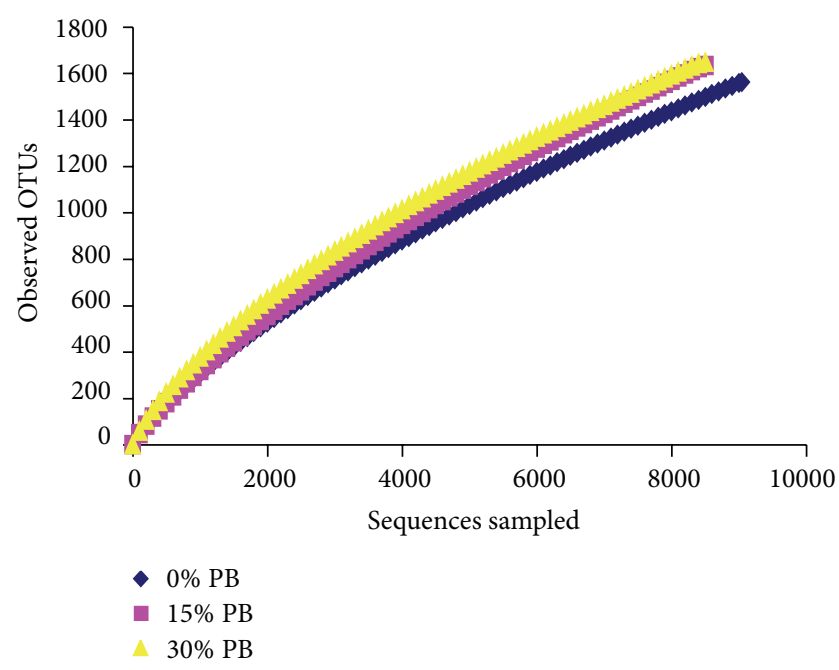

(b)

FIGURE 1: Bacterial richness/diversity estimator (a) and rarefaction curves (b) presented as calculated by MOTHUR at a level of 3\% dissimilarity. $0 \% \mathrm{~PB}$ (control), $15 \% \mathrm{~PB}$, and $30 \% \mathrm{~PB}$ on an as-fed basis.

and GenBank website at http://www.ncbi.nlm.nih.gov/. The sequences contained within the curated $16 \mathrm{~S}$ database were both $>1200 \mathrm{bp}$ and considered as high quality based upon RDP-II standards.

2.6. Data Processing and Statistical Analysis. All statistical analyses (Figures 1 to 6) were performed using the SPSS package (SPSS Inc., v 17.0, Chicago, IL). Relative abundance data are presented as percentages/proportions, but prior to subjection to GLM, they were transformed using the arcsine function for normal distribution prior to analysis. Package of NCSS (NCSS, 2007, v 7.1.2, Kaysville, UT) was used for cluster analysis through which double dendrograms were generated through use of the Manhattan distance method with no scaling and the unweighted pair technique. Raw sequences 


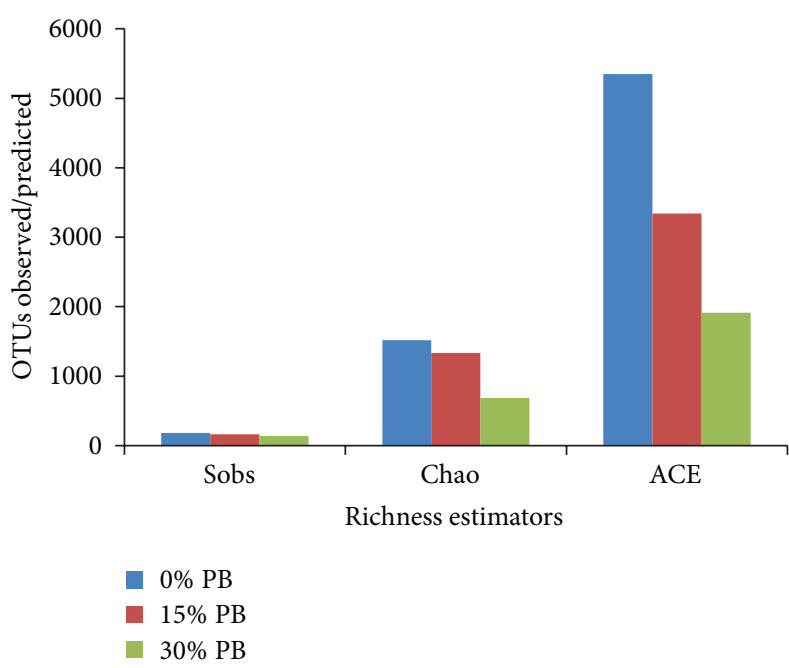

(a)

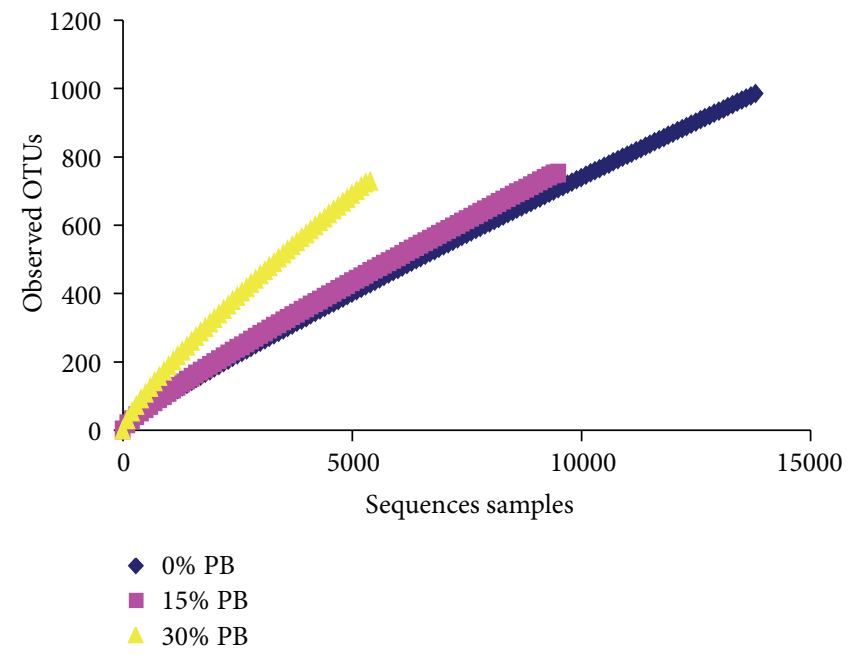

(b)

FIGURE 2: Fecal archaea richness/diversity estimator (a) and rarefaction curves (b) presented as calculated by MOTHUR at a level of 3\% dissimilarity. $0 \% \mathrm{~PB}$ (control), 15\% PB, and 30\% PB on an as-fed basis.

were submitted to the NCBI Sequence Read Archive (SRA). In addition, quantification of major hindgut bacterial and archaea populations (Tables 3 and 4) was analyzed by the GLM procedure of the SAS (SAS Inst., Cary, NC) in a completely randomized design with the factors examined being three levels of PB supplementation in the diets. Linear and quadratic effects were determined utilizing orthogonal polynomial contrasts for equally spaced treatments. Animals were the experimental unit and treated as a random effect. There were no treatment $\times$ period interactions $(P>0.10)$, hence only the main effects are reported for major microbial populations in the result section. Results are reported as least square means.

Quality trimmed sequences were provided with the sequencing services by the Research and Testing Laboratory (Lubbock, TX) [16]. Tags which did not have 100\% homology to the original sample tag designation were not included in data analysis. Sequences which were less than $250 \mathrm{bp}$ after quality trimming were not also considered. The B2C2 software [17], which is described and freely available from the Research and Testing Laboratory, was used to deplete samples of definite chimeras. Further processing and operational taxonomic units (OTUs) based analyses were then carried out using the MOTHUR v.1.19.4 [18] suite of algorithms for sequence processing and diversity analysis, including commands for identifying/consolidating unique sequences, filtering, multiple sequence alignment, generating distance matrices, and clustering of sequences into OTU. The resulting clusters were assessed at 3\% and 5\% dissimilarity to provide the data needed for diversity analysis. Based upon rarefaction [19], it is expected that $0 \%$ dissimilarity in sequences provides dramatic overestimation of the species present in a sample. The resulting sequences were then evaluated using the classify.seqs algorithm (Bayesian method) in MOTHUR against a database derived from the Greengenes set using a bootstrap cutoff of $65 \%$. The sequences contained within the curated
$16 \mathrm{~S}$ database were those considered as high quality based upon Greengenes [20] standards and which had complete taxonomic information within their annotations. Clusters at $3 \%$ and $5 \%$ were then utilized to generate rarefaction curves and the diversity indices ACE $[21,22]$ as well as unweighted and weighted UniFrac for Principle Coordinate Analysis (PCOA) plots and a Venn diagram.

\section{Results and Discussion}

Despite several decades of studies demonstrating the role of the ruminal and GI microbial diversity in ruminants associated with bacteria and archaea populations, the response of the microbial consortium to feeding various CT-containing diets remains largely unknown. The principal objective of this study was to assess the effects of CT-containing PB supplementation as a feed replacement on gastrointestinal methanogenic archaea and bacterial diversity dynamics in meat goats. The most significant findings in the present study was a decreased predominant fecal methanogenic genera Methanobrevibacter population (comprising up to $75 \%$ of the archaea population) as the level of PB supplement increased in the diet. The bacterial distribution showed that proteobacteria was the most dominant phyla with mean relative abundance values ranging from $46.5 \%$ in control to $47.1 \%$ in $15 \% \mathrm{~PB}$ and to $39.7 \%$ in $30 \% \mathrm{~PB}$ diets.

3.1. Diet Composition. Ingredients and chemical composition of experimental diet, $\mathrm{PB}$, WS, and $\mathrm{BGH}$ are presented in Table 1. Goats were provided diets that met all animals' requirements for growth and gain according to NRC [12]. Total CT concentration in the PB and WS was 10.3 and $0.03 \%$ $\mathrm{DM}$, respectively. However, grain mixes contained $0.19,1.63$, and $3.20 \%$ CT DM for the 0,15 , and $30 \%$ PB diet, respectively. All the experimental treatments provided similar nutrient 


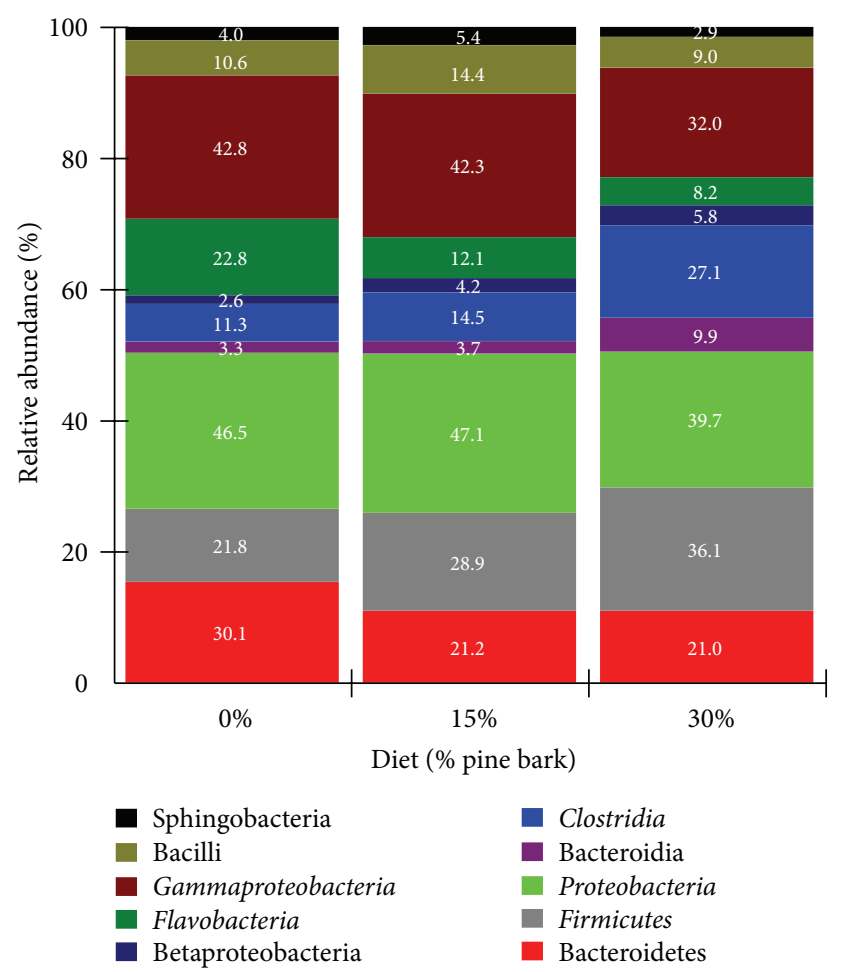

FIGURE 3: Relative abundance of major taxonomic groups across pine bark $(\mathrm{PB})$ dietary supplementation in growing meat goats. Phyla included in this figure had relative abundance values consistently greater than $1 \%$, as well as the abundant classes of the phylum Proteobacteria. Values presented are the mean percentage. $0 \%=0 \%$ PB (control), $15 \%=15 \% \mathrm{~PB}$, and $30 \%=30 \% \mathrm{~PB}$ on an as-fed basis.

profiles, except CT and acid detergent lignin that were higher in 15 and $30 \% \mathrm{~PB}$ ration. In our previous study, addition of $\mathrm{PB}$ in goat diets improved $\mathrm{ADG}$ and favorably modified ruminal fermentation [11].

3.2. Richness and Diversity Estimates. In the richness and diversity data in bacteria and archaea was presented in Figures 1 and 2, respectively. For bacteria, the maximum OTUs observed across the study were detected in control group, although the highest mean of bacterial richness was detected in the treatment group fed the 15\% PB diet (782.6; Figure 1(a)). Maximum OTUs were predicted for $\mathrm{CHAO}$ and ACE estimates with similar trends for the same sample as well. The trend of impact of PB in diet $(15 \%>30 \%>0 \%)$ was found in richness observations (sobs) that showed that the highest concentration of $\mathrm{PB}$ in the goat diet resulted in the lowest amount of bacteria detected in the feces while the control and 15\% diet showed very little difference. When calculating richness with Chao and ACE, the distinction between the treatments is more explicit as the 30\% diet remained the lowest, followed by the control and then the $15 \%$ diet. In calculating rarefaction curves richness estimates was found to be within Figure 1(b). It was hypothesized that bacterial community richness under CT-containing PB supplementation would differ due to inhibition of bacterial growth [23] and reduce fiber digestibility in the rumen [24].

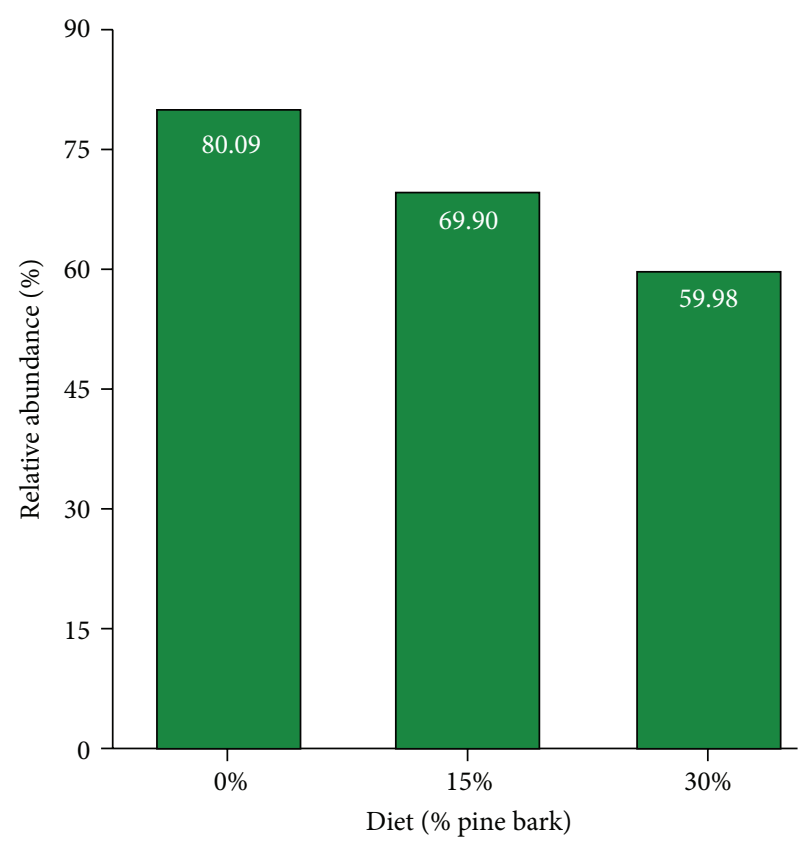

FIGURE 4: Relative abundance of major taxonomic group (Euryarchaeota) across pine bark (PB) dietary supplementation in growing meat goats. Phyla included in this figure had relative abundance values consistently greater than $1 \%$. Values presented are the mean percent. $0 \%=0 \% \mathrm{~PB}$ (control), $15 \%=15 \% \mathrm{~PB}$, and $30 \%=30 \% \mathrm{~PB}$ on an as-fed basis.

Smith et al. [9] reported that fecal bacterial population was affected by the presence of CT in the rat gastrointestinal tract.

When considering richness observations and estimates for archaeal community in the study, results demonstrate a vastly different trend (Figures 2(a) and 2(b)). Mean values for observed richness were consistently higher in the control treatment for all of the richness calculators. The trend observed of OTUs the highest mean value for the control (181), followed by the $15 \%$ diet (164), while the $30 \%$ diet remained the lowest (135; Figure 2(a)). The same trend was observed in the Chao and ACE estimates, as well as the OTUs observed in rarefaction. Furthermore, the Chao estimate appears to show the greatest coverage of the rarefaction peak values. The microbial community in the $30 \% \mathrm{~PB}$ supplemented group consistently showed the lowest values for richness in bacteria (Figures 1(a) and 1(b)) and archaea (Figures 2(a) and 2(b)).

It has been reported that the PB contained high level of CT [11] and polyphenolic compounds [25]. This chemical disturbance creates a microbial community with distinct abiotic and biotic characteristics, which impacts the growth and stability of gastrointestinal microbial community [26].

\subsection{Relative Abundance of Bacterial and Archaea Phyla.} Bacterial (Figure 3) and archaeal (Figure 4) community compositions of the feces were examined at descending levels of biological classification to were to determine the effect of PB supplementation on community membership. Detailed phylogenic analyses grouped the fecal bacteria associated 
bacterial sequences into 20 phyla (including unknown). The relative abundances of the 10 most abundant phyla are presented in Figure 3. The bacterial distribution showed that Proteobacteria was the most dominant phylum with mean relative abundance values ranging from $46.5 \%$ in control to 47.1 in $15 \% \mathrm{~PB}$ and to $39.7 \%$ in $30 \% \mathrm{~PB}$ diets. They include a wide variety of pathogens, such as Escherichia, Salmonella, Vibrio, Helicobacter, and many other notable genera [27]. Others are free-living, and include many of the bacteria responsible for nitrogen fixation. Other dominant phyla were Gammaproteobacteria (representing 32.0-42.8\% of the bacterial sequences in the samples) and Firmicutes and Bacteroidetes (which represented 21.0 to $36.1 \%$ of the bacterial sequences in each sample). The remaining phyla accounted for fewer than $25 \%$ of the relative abundance observed and were designated as minor. Of these groups, Gammaproteobacteria $(P<0.05)$, Flavobacteria $(P<0.01)$, Proteobacteria $(P<0.05)$, and Bacteroidetes $(P<0.05)$ were linearly decreased $(P<0.05)$ with increasing $P B$ diets. However, Clostridia $(P<0.01)$ and Firmicutes $(P<0.05)$ were linearly increased with increasing PB supplementation. This has been confirmed by the findings that Firmicutes, Bacteroidetes, Actinobacteria, and Proteobacteria were reported to be dominant bacterial phyla in the human gut [28].

The trend with respect to the one dominant archaea community group can be seen in Figure 4, in which the class of Euryarchaeota population was linearly decreased $(P<$ 0.01) with increasing PB diets. Collectively, the observed changes in frequency of occurrence depict dramatic shifts in fecal microbial communities associated with changes in diet in goats. It has been classified that Euryarchaeota, one of the meanwhile four kingdoms (or phyla) of the archaeal domain, consists of the strict anaerobic methanogens, the extreme halophiles, the hyperthermophilic Archaeoglobales and Thermococcales, and the cell wall free Thermoplasmatales $[29,30]$.

Tannins are phenolic plant secondary compounds and are widely distributed through the plant kingdom which affect animal performance and gut microorganisms. Tannins exist primarily in CT and hydrolysable tannins [7]. The hydrolysable tannins occur mainly in fruit pods and plant galls and unlike CT their degradation products are absorbed from the small intestine of animals [7] and are potentially toxic to ruminants. In contrast, $\mathrm{CT}$, unlike most compounds, is only partially absorbed in the small intestine in ruminants [31]. Most of the dietary CT reach the colon where simple phenolics and phenols (e.g., phenylacetic, mono- and dihydroxyphenylacetic acids, and protocatecuic acid) are produced by breakdown due to microbial activity [32]. Ultimately, these simple phenolics can be further metabolized to nonaromatics, such as short-chain fatty acids, lactate, succinate, ethanol, and the gases $\left(\mathrm{CO}_{2}\right.$ and $\mathrm{H}_{2}$ ) by the colonic microorganisms [28]. Therefore, the bacterial characterization of the gut microorganisms is surely important, but ultimately the enzymatic activity of its microorganisms becomes vital to map functional metabolic reactions and describe the interaction between host and its microbe to understand metabolism [28].

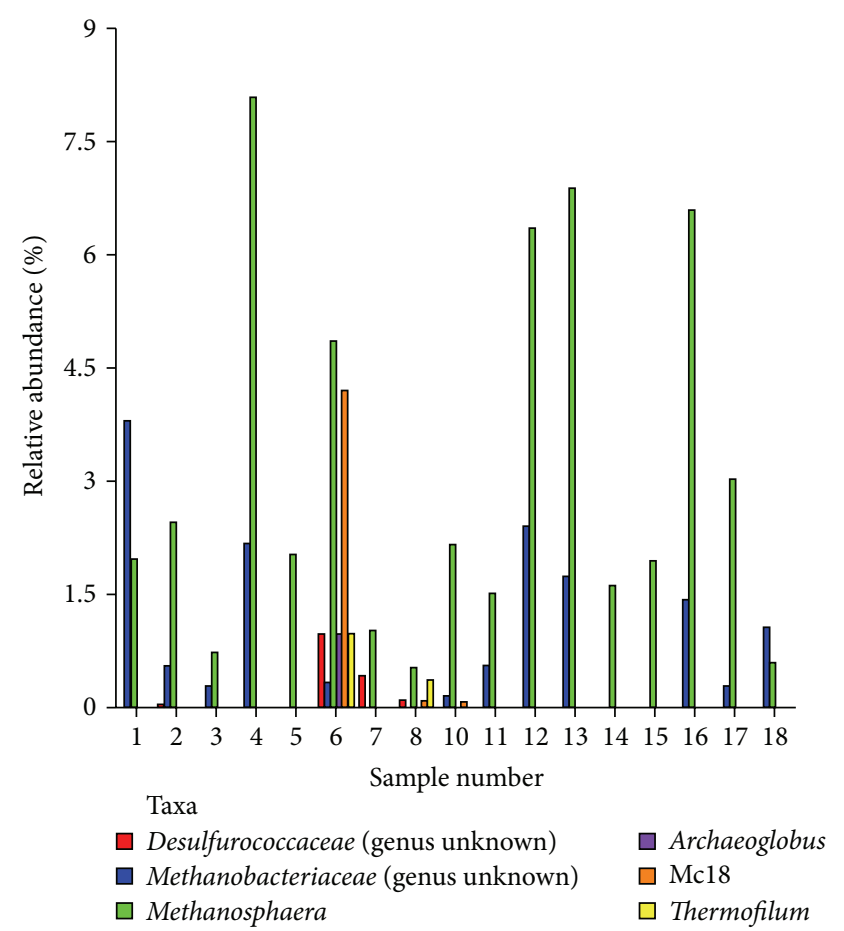

FIgURE 5: The 6 most abundant archaea genera (Methanobrevibacter, Desulfurococcaceae, Methanosphaera, Archaeoglobus, Mc18, and Thermofilum) in the hindgut of various levels of pine bark (PB) diets from a common cohort of 17 meat goats. Clustering in the $Y$ direction is indicative of abundance, not phylogenetic similarity. $0 \%$ $\mathrm{PB}($ control $)=$ sample $($ or tag $)$ number $1,2,3,4,5$, and $6 ; 15 \% \mathrm{~PB}=$ tag number $7,8,10,11$, and $12 ; 30 \% \mathrm{~PB}=\operatorname{tag}$ number $13,14,15,16,17$, and 18.

\subsection{Diversity and Abundance of Fecal Bacteria and Archaea.} For ease of presentation and interpretation, we present prevalent bacterial genera (Figure 5) and archaeal genera (Figure 6) community based on a cutoff value of $0.9 \%$ of relative community abundance for inclusion in a double dendogram cluster analysis of individual animal microbial diversity within and among diets in Figures 5 and 6. Overall, animals clustered relatively well within diet and animals. However, 15\% PB diet of one (tag number 12) animal clustered more closed to the control diet $(0 \% \mathrm{~PB})$. We attribute "misclassification" of this animal to greater relative abundance of Xanthomonadales, Clostridiales, Pseudomonadales, and Flavobacteriales and lower abundance (\%) of Mycoplasmatales and Bacteroidales compared with animals who received PB diet. Similar diversity trends in archaeal populations were observed on the same diets. For archaea, microbial archaea clustered vary between diets, but we classified these animals to greater relative abundance of Methanobacteriales and lower abundance of Archaeoglobus and Thermofilum between diets.

3.5. Quantitative Analyses. So far, only a limited number of bacterial species have been identified as being involved in the metabolism of CT and polyphenols, and little is known about the microbial populations in the hindgut of the goat. The metabolic activities of the bacteria and archaea 


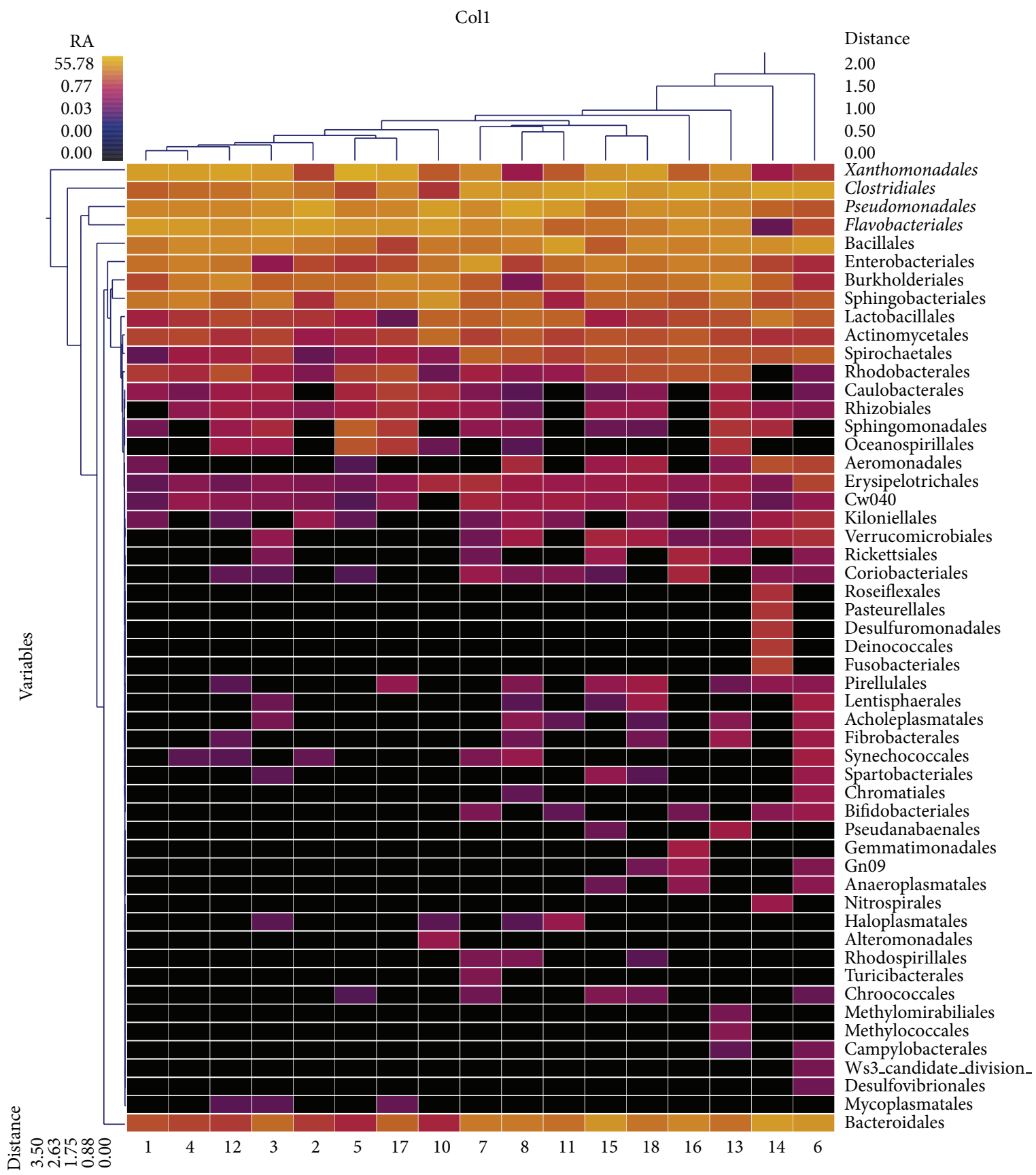

FIGURE 6: Thermal double dendrogram of the 53 most abundant bacterial genera in the hindgut of various levels of pine bark (PB) diets from a common cohort of 17 meat goats. Clustering in the $Y$ direction is indicative of abundance, not phylogenetic similarity. RA $=$ relative abundance; $0 \% \mathrm{~PB}($ control $)=\operatorname{tag}$ number $1,2,3,4,5$, and $6 ; 15 \% \mathrm{~PB}=\operatorname{tag}$ number $7,8,10,11$, and 12; $30 \% \mathrm{~PB}=\operatorname{tag}$ number $13,14,15,16,17$, and 18.

in the gut are very important in determining the healthy functioning and methane gas emissions from the gut. For further quantification of major hindgut bacterial and archaeal species diversity populations in meat goats $(n=6)$ are presented in Tables 3 and 4, respectively. For bacterial species, Stenotrophomonas koreensis was the most dominant bacterial species with mean relative abundance values ranging from $23.9 \%$ (control) to $9.9 \%(15 \% \mathrm{~PB})$ and $17.2 \%$ (30\% PB). The remaining bacterial species accounted for fewer than $10 \%$ of the relative abundance observed. Of these groups, Flavobacterium gelidilacus $(P<0.02)$ and Myroides odoratimimus $(P=0.09)$ were decreased $(P<0.05)$ with increasing dietary $\mathrm{PB}$ concentration. However, Bacteroides capillosus $(P<0.02)$, Clostridium orbiscindens $(P<0.03)$, and Oscillospira guilliermondii $(P=0.06)$ were linearly increased with increasing $\mathrm{PB}$ concentration. This finding agrees with the results of a metabolic finger print patterns study of a rat fed CT extract from Acacia angustissima. Condensed 
TABLE 3: Quantification of major hindgut bacterial diversity present in meat goat $(n=6)$ as analyzed using bTEFAP pyrosequencing method ${ }^{1}$.

\begin{tabular}{|c|c|c|c|c|c|c|}
\hline \multirow{2}{*}{ Item } & \multicolumn{3}{|c|}{ Diets $^{2}$} & \multirow{2}{*}{ SEM } & \multicolumn{2}{|c|}{$P$ values ${ }^{3}$} \\
\hline & Control & $15 \% \mathrm{~PB}$ & $30 \% \mathrm{~PB}$ & & $\mathrm{~L}$ & Q \\
\hline Acinetobacter haemolyticus & 1.1 & 1.2 & 0.2 & 0.06 & 0.32 & 0.54 \\
\hline Acinetobacter lwoffii & 7.0 & 6.5 & 0.3 & 3.70 & 0.22 & 0.56 \\
\hline Acinetobacter radioresistens & 1.4 & 4.2 & 1.1 & 0.92 & 0.80 & 0.03 \\
\hline Acinetobacter rhizosphaerae & 1.1 & 1.5 & 0.9 & 0.47 & 0.76 & 0.39 \\
\hline Acinetobacter schindleri & 3.4 & 8.5 & 5.3 & 0.82 & 0.46 & 0.11 \\
\hline Bacteroides capillosus & 0.5 & 1.1 & 2.7 & 0.60 & 0.02 & 0.52 \\
\hline Clostridium orbiscindens & 0.02 & 1.4 & 2.3 & 0.48 & 0.03 & 0.92 \\
\hline Comamonas aquatica & 2.4 & 3.9 & 4.7 & 1.43 & 0.25 & 0.88 \\
\hline Enterobacter hormaechei & 0.8 & 3.3 & 2.0 & 0.95 & 0.42 & 0.16 \\
\hline Escherichia albertii & 0.6 & 1.5 & 0.9 & 0.53 & 0.73 & 0.25 \\
\hline Escherichia fergusonii & 0.6 & 1.9 & 1.2 & 0.60 & 0.49 & 0.18 \\
\hline Flavobacterium columnare & 0.4 & 2.0 & 0.5 & 0.83 & 0.91 & 0.18 \\
\hline Flavobacterium gelidilacus & 5.81 & 1.2 & 1.7 & 1.14 & 0.02 & 1.10 \\
\hline Flavobacterium succinicans & 1.7 & 0.2 & 1.3 & 1.80 & 0.58 & 0.15 \\
\hline Myroides odoratimimus & 7.8 & 4.5 & 1.2 & 2.58 & 0.09 & 0.99 \\
\hline Oscillospira guilliermondii & 0.99 & 1.2 & 3.0 & 0.69 & 0.06 & 0.38 \\
\hline Sphingobacterium faecium & 1.2 & 4.4 & 0.53 & 1.09 & 0.83 & 0.16 \\
\hline Sphingobacterium mizutaii & 1.8 & 0.6 & 1.4 & 0.41 & 0.40 & 0.07 \\
\hline Stenotrophomonas koreensis & 23.9 & 9.9 & 17.2 & 7.40 & 0.53 & 0.28 \\
\hline Rummeliibacillus pycnus & 8.54 & 9.9 & 6.9 & 0.35 & 0.75 & 0.63 \\
\hline
\end{tabular}

${ }^{1}$ Data were presented with a cutoff value of $0.9 \%$.

${ }^{2}$ Control (0\% PB), $15 \% \mathrm{~PB}$, and $30 \% \mathrm{~PB}$ on an as-fed basis.

${ }^{3}$ Polynomial contrasts for equally spaced treatments.

L: linear effect; Q: quadratic effect.

TABLE 4: Quantification of hindgut methanogenic archaea diversity present in meat goat $(n=6)$ as analyzed using bTEFAP pyrosequencing method $^{1}$.

\begin{tabular}{lccccc}
\hline Item & & Diets $^{2}$ & & SEM & \multicolumn{2}{c}{$\begin{array}{c}\text { L values } \\
\end{array}$} & Control & $15 \%$ PB & $30 \%$ PB & 49.6 & 8.84 & 0.05 \\
\hline Methanobrevibacter spp. & 74.8 & 71.7 & 0.74 & 0.45 & 0.43 \\
Methanosphaera spp. & 1.18 & 0.61 & 3.44 & 1.01 & 0.51 \\
Methanobacteriaceae spp. & 3.35 & 2.31 & 0.95 & 0.44 \\
\hline
\end{tabular}

${ }^{1}$ Data were presented with a cutoff value of $0.9 \%$.

${ }^{2}$ Control $(0 \%$ PB), $15 \%$ PB, and $30 \%$ PB on an as-fed basis.

${ }^{3}$ Polynomial contrasts for equally spaced treatments. L: linear effect; Q: quadratic effect.

tannin extracts from $A$. angustissima altered fecal bacterial populations in the gastrointestinal tract, resulting in a shift in the predominant bacteria towards tannin-resistant gramnegative Enterobacteriaceae and Bacteroidetes [9]. In contrast, the gastrointestinal microbial population was significantly different in cattle, dominated by Prevotella $(18.2 \%$ of total population) in the rumen and Clostridium (19.7\% of total population) in the feces [29]. Interestingly, the majority of the bacteria in the human gut recorded belongs to the Clostridia group, which is a large component of the gut microbiota [28].

Condensed tannins from green tea catechins, which are monomeric polyphenols, have also been shown to cause a shift in bacteria populations. Polyphenolics from green tea affect gastrointestinal bacteria in humans $[28,30]$, chickens $[33,34]$, and pigs [35]. In the human study, 4 weeks of consuming a polyphenolic content equivalent to 10 cups of concentrated green tea were necessary for there to be a great decrease in Clostridium species and Clostridium perfringens. Other groups of bacteria, including the Bacteroidaceae, were not affected [29, 30]. However, Moco et al. [28] reported that diet containing polyphenols (e.g., +catechin) increased the growth of the Clostridium coccoides, Eubacterium rectale, Bifidobacterium spp., and Escherichia coli, but significantly decreased the growth of the Clostridium histolyticum group. In chickens the levels of cecal lactobacilli increased significantly, while the levels of Enterobacteriaceae decreased [33, 34]. All these studies confirmed that CT cause a shift in the bacterial population in the intestinal tract, and a consistent result is that gram-positive bacterial groups are decreased.

The relative abundances of the 4 most abundant ( $>0.9 \%)$ archaea species are presented in Table 4. Predominant hindgut archaeal species among methanogens were 
Methanobrevibacter $(75,72$, and 49\%), Methanosphaera (3.3, 2.3, and 3.4\%), and Methanobacteriaceae (1.2, 0.6, and 0.7\%) population in control, 15 , and $30 \% \mathrm{~PB}$, respectively, and they were linearly decreased or increased with increasing $\mathrm{PB}$ concentration $(P<0.05)$. The effect of CT in forages upon interactions between rumen bacteria and plant protein has been proposed [7]. It has been suggested that the proteolysis of soluble proteins in the rumen is affected, primarily by cellassociated proteinases on the rumen bacteria. Furthermore, $\mathrm{CT}$ in the diets have been shown to induce changes in morphology of several species of rumen bacteria [7]. Inhibition of rumen microorganisms by CT is probably due to CT:substrate (microorganisms) interactions [7]. One of the possible explanations for the decrease in Methanobrevibacter spp. prevalence is assumed to be linked to the substantial relationship between these archaea and protozoa [6] and the protozoa and subsequent reduction in reducing equivalent $\left(\mathrm{H}_{2}\right)$ cross-feeding between archaea and protozoa [36]. Condensed tannins are known to decrease protozoal number [37], and the decrease in methane production could also be mediated through decrease in protozoal number. Tavendale et al. [38] suggested two models of impacting methanogenesis: first, directly affecting activity or population of methanogens, resulting in lower methane emission, and, second, indirectly by reduced hydrogen production by lowering feed degradation. However, the possible mechanisms and effects of CT-containing diets on gastrointestinal methanogenesis and its mode of action are not clearly understood. More in vivo studies with a wide range of tannins sources (types) need to be conducted to evaluate the full potential of tannins. In addition, there is a lack of knowledge of a systematic and preventive process control from the anthropogenic emissions of $\mathrm{CH}_{4}, \mathrm{H}_{2}$, and volatile fatty acids and its relationship with microbial community.

\section{Conflict of Interests}

The authors declare that they have no conflict of interests.

\section{Acknowledgment}

This work was supported by the J.W. Cover Caprine Research and Education Center, Tuskegee University.

\section{References}

[1] D. O. Krause and J. B. Russell, "How many ruminal bacteria are there?” Journal of Dairy Science, vol. 79, no. 8, pp. 1467-1475, 1996.

[2] J. E. Edwards, N. R. McEwan, A. J. Travis, and R. J. Wallace, "16S rDNA library-based analysis of ruminal bacterial diversity," Antonie van Leeuwenhoek, vol. 86, no. 3, pp. 263-281, 2004.

[3] P. B. Eckburg, E. M. Bik, C. N. Bernstein et al., "Microbiology: diversity of the human intestinal microbial flora," Science, vol. 308, no. 5728, pp. 1635-1638, 2005.

[4] R. E. Ley, D. A. Peterson, and J. I. Gordon, "Ecological and evolutionary forces shaping microbial diversity in the human intestine," Cell, vol. 124, no. 4, pp. 837-848, 2006.
[5] D. W. Pitta, W. E. Pinchak, S. E. Dowd et al., "Rumen bacterial diversity dynamics associated with changing from bermudagrass hay to grazed winter wheat diets," Microbial Ecology, vol. 59, no. 3, pp. 511-522, 2010.

[6] A. N. Hristov, T. R. Callaway, C. Lee, and S. E. Dowd, "Rumen bacterial, archaeal, and fungal diversity of dairy cows in response to lauric or myristic acids ingestion," Journal of Animal Science, vol. 90, pp. 4449-4457, 2012.

[7] B. R. Min, T. N. Barry, G. T. Attwood, and W. C. McNabb, "The effect of condensed tannins on the nutrition and health of ruminants fed fresh temperate forages: a review," Animal Feed Science and Technology, vol. 106, no. 1-4, pp. 3-19, 2003.

[8] B. R. Min, G. T. Attwood, K. Reilly et al., "Lotus corniculatus condensed tannins decrease in vivo populations of proteolytic bacteria and affect nitrogen metabolism in the rumen of sheep," Canadian Journal of Microbiology, vol. 48, no. 10, pp. 911-921, 2002.

[9] A. H. Smith, J. A. Imlay, and R. I. Mackie, "Increasing the oxidative stress response allows Escherichia coli to overcome inhibitory effects of condensed tannins," Applied and Environmental Microbiology, vol. 69, no. 6, pp. 3406-3411, 2003.

[10] S. E. Dowd, T. R. Callaway, R. D. Wolcott et al., "Evaluation of the bacterial diversity in the feces of cattle using $16 \mathrm{~S}$ rDNA bacterial tag-encoded FLX amplicon pyrosequencing (bTEFAP)," BMC Microbiology, vol. 8, article no. 125, 2008.

[11] B. R. Min, S. Solaiman, N. Gurung et al., "Effects of pine bark supplementation on performance, rumen fermentation, and carcass characteristics of Kiko crossbred male goats," Journal of Animal Science, vol. 90, pp. 3556-3567, 2012.

[12] National Research Council (NRC), Nutrient Requirement of Sheep, Goats, Cervids and Camelids, Academy Press, Washington, DC, USA, 2007.

[13] AOAC, Official Methods of Analysis, Association of Official Analytical Chemists, Gaithersburg, Md, USA, 16th edition, 1998.

[14] S. E. Dowd, K. Killinger-Mann, M. Brashears, and J. Fralick, "Evaluation of gene expression in a single antibiotic exposurederived isolate of Salmonella enterica Typhimurium 14028 possessing resistance to multiple antibiotics," Foodborne Pathogens and Disease, vol. 5, no. 2, pp. 205-221, 2008.

[15] S. F. Altschul, W. Gish, W. Miller, E. W. Myers, and D. J. Lipman, "Basic local alignment search tool," Journal of Molecular Biology, vol. 215, no. 3, pp. 403-410, 1990.

[16] J. R. Cole, B. Chai, R. J. Farris et al., “The Ribosomal Database Project (RDP-II): sequences and tools for high-throughput rRNA analysis," Nucleic Acids Research, vol. 33, pp. D294-D296, 2005.

[17] V. Gontcharova, E. Youn, R. D. Wolcott et al., "Black Box Chimera Check (B2C2): a windows-based software for batch distinct bacterial communities in agroecosystem," Open Microbiological Journal, vol. 4, pp. 47-52, 2010.

[18] P. D. Schloss, S. L. Westcott, T. Ryabin et al., "Introducing mothur: open-source, platform-independent, communitysupported software for describing and comparing microbial communities," Applied and Environmental Microbiology, vol. 75, no. 23, pp. 7537-7541, 2009.

[19] L. F. W. Roesch, R. R. Fulthorpe, A. Riva et al., "Pyrosequencing enumerates and contrasts soil microbial diversity," The ISME Journal, vol. 1, no. 4, pp. 283-290, 2007. 
[20] T. Z. DeSantis, P. Hugenholtz, N. Larsen et al., "Greengenes, a chimera-checked $16 \mathrm{~S}$ rRNA gene database and workbench compatible with ARB," Applied and Environmental Microbiology, vol. 72, no. 7, pp. 5069-5072, 2006.

[21] A. Chao and M. C. K. Yang, "Stopping rules and estimation for recapture debugging with unequal failure rates," Biometrika, vol. 80, no. 1, pp. 193-201, 1993.

[22] A. Chao, "Nonparametric estimation of the number of classes in a population," Scandinavian Journal of Statistic, vol. 11, pp. 265270, 1984.

[23] B. R. Min, G. T. Attwood, W. C. McNabb, A. L. Molan, and T. N. Barry, "The effect of condensed tannins from Lotus corniculatus on the proteolytic activities and growth of rumen bacteria," Animal Feed Science and Technology, vol. 121, no. 1-2, pp. 45-58, 2005.

[24] B. R. Min, S. Solaiman, R. Shange et al., "Effect of feeding tannin-containing pine bark on fecal bacterial population and methane gas production in Kiko-cross goats," Journal of Animal Science, vol. 89, p. 427, 2011.

[25] J. J. Karchesy and R. W. Hemingway, "Loblolly pine bark polyflavanoids," Journal of Agricultural and Food Chemistry, vol. 28, no. 2, pp. 222-228, 1980.

[26] G. Selvakumar, S. Saha, and S. Kundu, "Inhibitory activity of pine needle tannin extracts on some agriculturally resourceful microbes," Indian Journal of Microbiology, vol. 47, no. 3, pp. 267270, 2007.

[27] E. Stackebrandt, R. G. E. Murray, and H. G. Truper, "Proteobacteria classis nov., a name for the phylogenetic taxon that includes the 'purple bacteria and their relatives"' International Journal of Systematic Bacteriology, vol. 38, no. 3, pp. 321-325, 1988.

[28] S. Moco, F. P. J. Matin, and S. Rezzi, "Metabolomics view on gut microbiome modulation by polyphenol rich foods," Journal of Proteome Research, vol. 11, pp. 4781-4790, 2012.

[29] T. R. Callaway, S. E. Dowd, T. S. Edrington et al., "Evaluation of bacterial diversity in the rumen and feces of cattle fed different levels of dried distillers grains plus solubles using bacterial tag-encoded FLX amplicon pyrosequencing," Journal of Animal Science, vol. 88, no. 12, pp. 3977-3983, 2010.

[30] J.-C. Cho, K. L. Vergin, R. M. Morris, and S. J. Giovannoni, "Lentisphaera araneosa gen. nov., sp. nov, a transparent exopolymer producing marine bacterium, and the description of a novel bacterial phylum, Lentisphaerae," Environmental Microbiology, vol. 6, no. 6, pp. 611-621, 2004.

[31] T. H. Terrill, G. C. Waghorn, D. J. Woolley, W. C. McNabb, and T. N. Barry, "Assay and digestion of 14C-labelled condensed tannins in the gastrointestinal tract of sheep," British Journal of Nutrition, vol. 72, no. 3, pp. 467-477, 1994.

[32] M. V. Selma, J. C. Espín, and F. A. Tomás-Barberán, "Interaction between phenolics and gut microbiota: role in human health," Journal of Agricultural and Food Chemistry, vol. 57, no. 15, pp. 6485-6501, 2009.

[33] Y. Hara, "Influence of tea catechins on the digestive tract," Journal of Cell Biochemistry. Supplement, vol. 27, pp. 52-58, 1997.

[34] X. Shi, C. Xiao, Y. Wang, and H. Tang, "Gallic acid intake induces alterationsto systems metabolism in rats," Journal of Proteome Research, vol. 12, pp. 991-1006, 2012.

[35] H. Hara, N. Orita, S. Hatano et al., "Effect of tea polyphenols on fecal flora and fecal metabolic products of pigs," The Journal of Veterinary Medical Science, vol. 57, no. 1, pp. 45-49, 1995.
[36] G. D. Vogels, W. F. Hoppe, and C. K. Stumm, "Association of methanogenic bacteria with rumen ciliates," Applied and Environmental Microbiology, vol. 40, no. 3, pp. 608-612, 1980.

[37] H. P. Makkar, M. Blummel, and K. Becker, "In vitro effects of and interactions between tannins and saponins and fate of tannins in the rumen," Journal of the Science of Food and Agriculture, vol. 69, no. 4, pp. 481-493, 1995.

[38] M. H. Tavendale, G. A. Lane, N. M. Schreurs, K. Fraser, and L. P. Meagher, "The effects of condensed tannins from Dorycnium rectum on skatole and indole ruminal biogenesis for grazing sheep," Australian Journal of Agricultural Research, vol. 56, no. 12, pp. 1331-1337, 2005. 

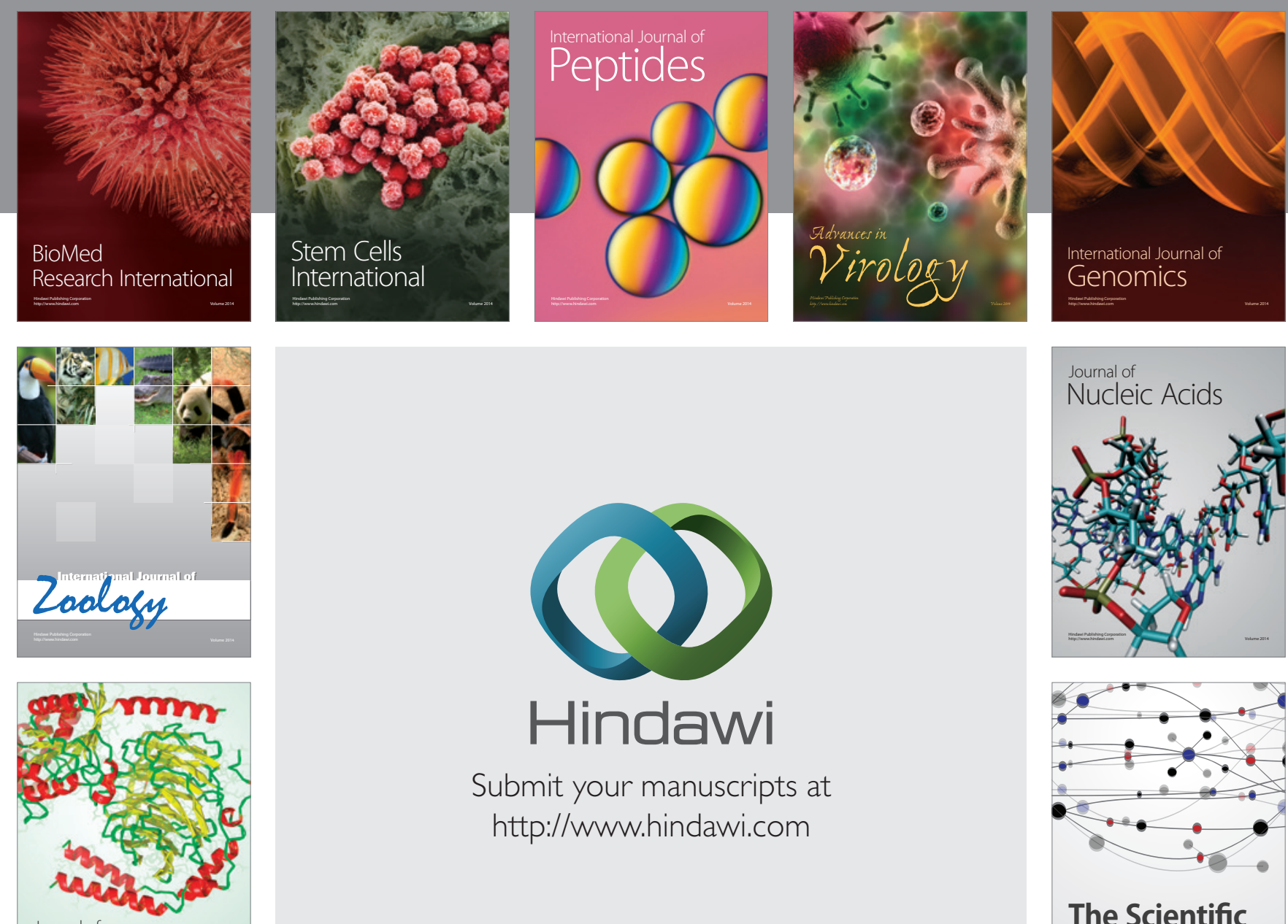

Submit your manuscripts at

http://www.hindawi.com

Journal of
Signal Transduction
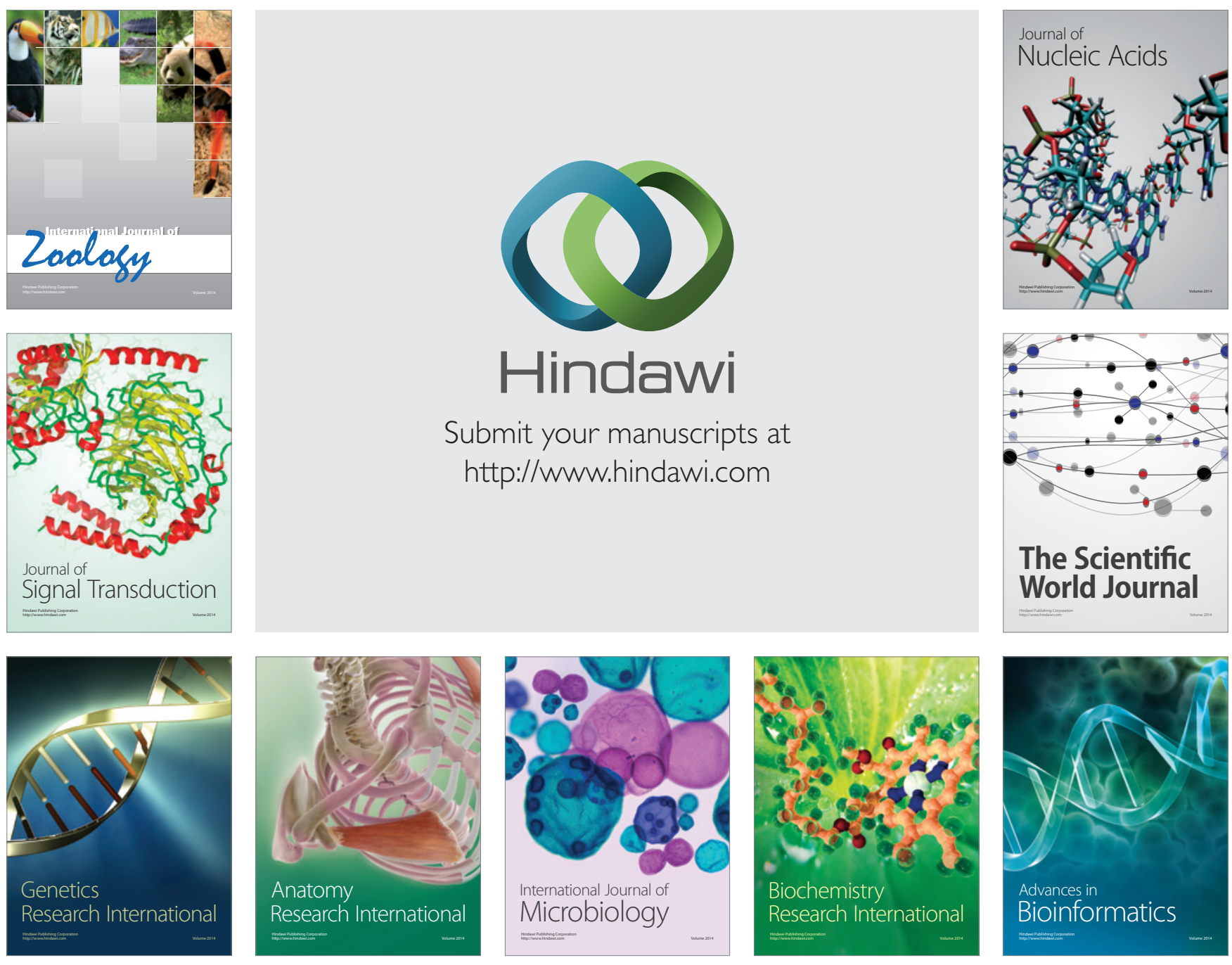

The Scientific World Journal
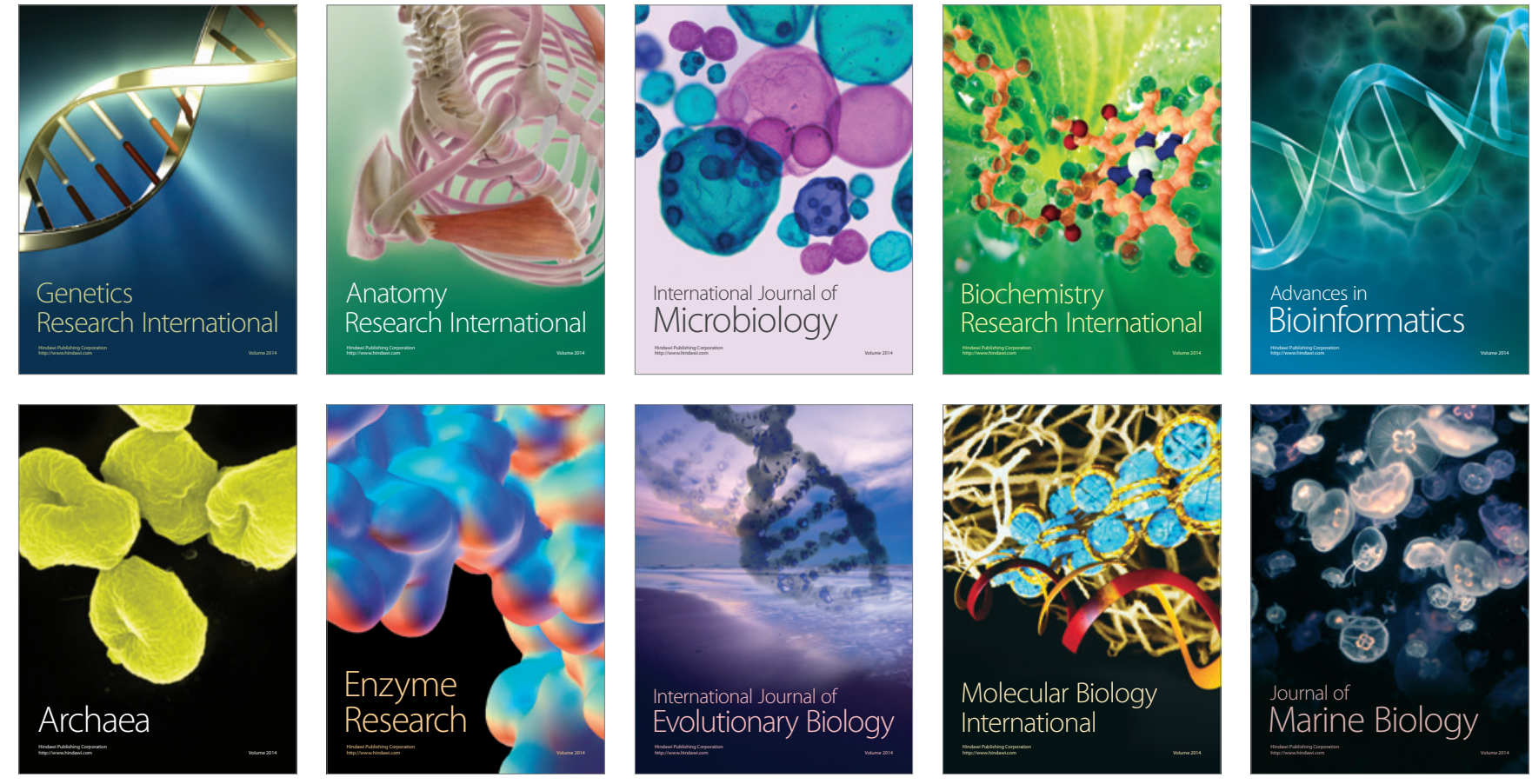